\title{
Optimal retrofitting measures for residential buildings at large scale: a multi-objective approach
}

\author{
Portia Murray $^{1,2}$, Mathias Niffeler ${ }^{1,2}$, Georgios Mavromatidis ${ }^{1,2}$, Kristina Orehounig ${ }^{1}$ \\ ${ }^{1}$ Urban Energy Systems Laboratory, Empa, Duebendorf, Switzerland \\ ${ }^{2}$ Chair of Building Physics, ETH Zurich, Zurich, Switzerland
}

\begin{abstract}
The goal of this research effort is to identify an optimal set of energy efficiency measures and renewable and highly efficient energy systems for a large-scale building stock. To reach this goal, a simulation and optimization framework is developed which represents the overall heterogeneity of the building stock, and allows for the investigation the optimal set of building measures based on multi-criteria decision making such as costs, $\mathrm{CO}_{2}$ emissions, energy consumption, etc. The developed methodology is applied on a set of archetypical buildings of the Swiss residential building stock to assess the effectiveness of different measures in reaching emission reduction targets. Subsequently the solutions are upscaled to the overall building stock to give recommendations for specific regions or countries and identify their potential impact.
\end{abstract}

\section{Introduction}

The building stock in European countries contributes significantly to current $\mathrm{CO}_{2}$ emissions. To reach climate targets of the future, greenhouse gas emissions have to be reduced, and thus buildings have to become more energy efficient and fossil fuel based systems have to be replaced by renewable energy based solutions or highly efficient solutions, such as heat pumps. Technical energy regulations can be very effective to implement these energy efficiency measures. However, with recent developments in new technologies (such as decentralized energy systems, urban energy systems, energy storage systems etc.) existing regulations have to be revised to account for those novel developments. Within a research project, we are investigating the set of optimal energy efficiency measures and renewable based energy systems for the current building stock of Switzerland to reach the targets of the Swiss energy strategy (Prognos 2012). In this research, new methods, concepts and elements for the investigation of optimal measures for the building stock are developed and the most promising measures are identified. These measures will potentially be considered in future technical energy regulations of Switzerland. A simulation and optimization approach is developed which represents the overall heterogeneity of the building stock, and allows for investigation of the optimal set of building measures based on multi-criteria decision making such as costs, $\mathrm{CO}_{2}$ emissions, energy consumption, etc. The developed methodology can be used to assess the effectiveness of energy efficiency measures to reach emission reduction targets, but also allows to upscale solutions to the overall building stock of regions or countries to identify their potential impact.

\section{Method}

The approach of this study includes the following steps. First, a representative subsample of the overall building stock is generated through clustering methods of different data sources, which represent buildings, neighborhoods and the current and future energy sources. Secondly, the current energy consumption is assessed including different retrofitting and energy efficiency measures at individual building level. Results of this analysis act as input information for a multi-objective linear optimization model to examine optimal solutions in terms of building envelope and building system interventions. In a final step, the method is applied to the overall building stock of Switzerland, and the optimal set of measures and systems are identified. The approach with the individual steps is depicted in Figure 1. The analysis is applied on approximately 440000 single family and 230000 multi-family buildings of Switzerland for which data of sufficient quality could be gathered.

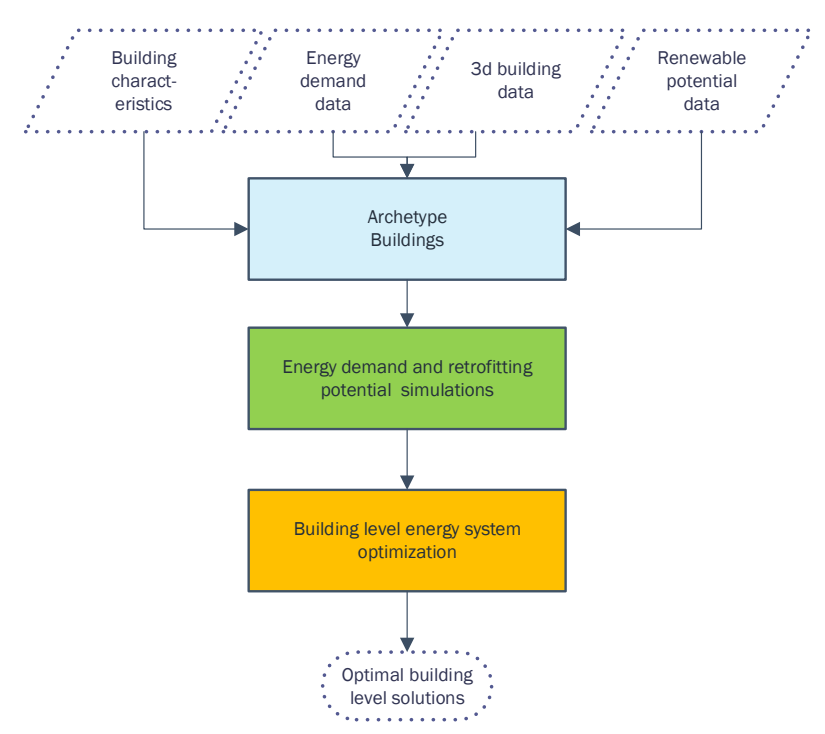

Figure 1. Workflow for assessing optimal solutions

\section{Archetype buildings}

To define representative - so called archetype buildings of the Swiss building stock, clustering techniques on 
various building characteristics are deployed. Thereby information such as building area, age of the building, energy demand, climatic region or renewable energy potential is important to know, but also information on how different buildings react to retrofitting and system interventions. Unfortunately, information on the latter aspect is typically not available. It requires in-depth analysis of individual buildings to determine their responses to different retrofits and energy system interventions. Since the overall building stock of Switzerland is composed of about 1.8 Million buildings, simulations required in this case are too time- and computationally intensive to be performed for the entire building stock. Consequently, a reasonably small subsample needs to be selected that represents the whole building stock in a sufficient manner.

Within this research, building level information has been collected for the overall building stock of Switzerland. Information is gathered from three main sources, which are provided by the Federal Office for Statistics (BFS), by the Swiss Competence Centre for Energy Research (SCCER), and by the Federal Office for Topography (swisstopo). Respective databases pertain to the Swiss building- and apartment-registry (BFS 2013), where information on individual buildings is available. Additionally SCCER's geo-dependent energy supply/demand web service (Schneider 2018) was used, which provides estimations of average heat demand of Swiss buildings on a per-area basis (squares of $200 \mathrm{~m}$ by $200 \mathrm{~m}$ ) and heating demands of each individual building. Additionally, Swisstopo data on geometry information is used (Swisstopo 2016) to evaluate floor area and height of buildings. Relevant features, which are used for the clustering, are summarized in Table 1. After combining the different building databases and cleaning the dataset, a total of approximately 800 ' 000 buildings are remaining. Among those, 230'000 are multi-family houses and approximately 440 '000 are single-family houses. The remaining buildings pertain to the public, industrial or commercial sector.

For the clustering analysis, the nearest neighbor algorithm (from the Scikit-learn python toolbox) was selected (Pedregosa et al. 2011), which relies on the Euclidean distance as a measure of similarity between the different data points, i.e. the buildings in this case. This algorithm finds a pre-defined number of points, which are closest in distance to new points in order to predict the cluster. To avoid skewed results, the range of values a feature can take on, needs to be similar across all features. Furthermore, the selection algorithm depends on nearest neighbor calculations for the successive elimination of data points. Since nearest neighbor calculations are often very computationally intensive for large databases, one way to reduce computational intensity is to reduce the feature space in which the nearest neighbors shall be calculated. The selection algorithm therefore considers only the most important building properties, which pertain to physical building features, like building height and floor area, and features describing the energy system.
Table 1: Features available at a building-level and their corresponding sources

\begin{tabular}{|c|c|c|c|}
\hline \multirow{2}{*}{ Features } & \multicolumn{3}{|c|}{ Databases by: } \\
\hline & $B F S$ & SCCER & swisstopo \\
\hline GIS building code & & & $x$ \\
\hline $\begin{array}{l}\text { Identifier of } \\
\text { municipality }\end{array}$ & $x$ & $x$ & $x$ \\
\hline Identifier of canton & $x$ & $x$ & $x$ \\
\hline Postal code & $x$ & & \\
\hline Building coordinates & $x$ & $x$ & $x$ \\
\hline $\begin{array}{l}\text { Classification of } \\
\text { construction zone }\end{array}$ & & & $x$ \\
\hline Building category BFS & $x$ & & \\
\hline $\begin{array}{l}\text { Building category } \\
\text { SCCER }\end{array}$ & & $x$ & \\
\hline $\begin{array}{l}\text { Number of dwellings in } \\
\text { building }\end{array}$ & $x$ & & \\
\hline Number of residents & $x$ & & \\
\hline $\begin{array}{l}\text { Number of main } \\
\text { residents }\end{array}$ & $x$ & & \\
\hline Construction period & $x$ & & \\
\hline Number of floors & $x$ & & \\
\hline Building height & & & $x$ \\
\hline Ground floor area & & & $x$ \\
\hline Total floor area & & $x$ & $x$ \\
\hline $\begin{array}{c}\text { Estimated total heated } \\
\text { surface }\end{array}$ & & x & \\
\hline Heating system & $x$ & & \\
\hline $\begin{array}{l}\text { Energy carrier for } \\
\text { heating }\end{array}$ & $x$ & $x$ & \\
\hline $\begin{array}{l}\text { Availability of hot } \\
\quad \text { water }\end{array}$ & $x$ & & \\
\hline $\begin{array}{c}\text { Energy carrier for hot } \\
\text { water }\end{array}$ & & $x$ & \\
\hline Heating demand & & $x$ & \\
\hline $\begin{array}{c}\text { Domestic hot water } \\
\text { demand }\end{array}$ & & $x$ & \\
\hline $\begin{array}{c}\text { Final energy demand } \\
\text { for heating\& domestic } \\
\text { hot water }\end{array}$ & & $x$ & \\
\hline
\end{tabular}

The algorithm used here for the selections of a representative subsample of buildings can be described by the following steps:

1. All buildings receive an index. It is also associated to their corresponding data point in the feature space. The feature space can be thought of as an n-dimensional space in which each feature (i.e. each building property) represents one dimension.

2. Relevant building properties are selected, in order to reduce the feature space.

3. The remaining features are standardized based on the following equation: 


$$
f_{j, s t d}^{i}=\frac{f_{j}^{i}-\overline{f^{\imath}}}{\sigma_{f^{i}}}, \forall i \in\{1, \ldots, n\} \text { and } \forall j \in\{1, \ldots, m\}
$$

where $f_{j}^{i}$ is the $i$ th feature of the $j$ th building. $n$ and $m$ are the total number of features and buildings used in the selection algorithm, respectively. $\bar{f}^{\imath}$ refers to the mean of the $i$ th feature across all buildings and $\sigma_{f} i$ is the corresponding standard deviation.

4. In an iterative process, the nearest neighbor is determined for each data point (i.e. each building), after this, the one datapoint with the closest nearest neighbor is eliminated from the remaining dataset.

This clustering approach is applied on the selected buildings, and the resulting archetypes are used for identifying relevant measures.

\section{Identified retrofitting measures}

Measures at building level have been identified, which improve, on the one hand, the energy efficiency of buildings, and on the other hand reduce $\mathrm{CO}_{2}$ emissions. These measures can be structured in to energy system measures, building envelope interventions and general energy efficiency measures within the building (summarized in Table 2). The measures are then evaluated with the above-mentioned framework, thereby building envelope and energy efficiency measures are simulated with step 2, the energy demand calculations, and the optimal energy system selection together with the optimal retrofitting selection is then evaluated with the optimization tool in step 3 .

Table 2: List of investigated measures

\begin{tabular}{|c|c|}
\hline & Considered measures at building level \\
\hline \multirow{6}{*}{ 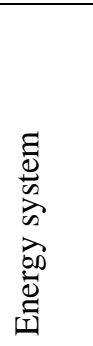 } & PV and Solar thermal (ST) \\
\hline & GSHP and ASHP \\
\hline & $\begin{array}{l}\text { Biomass (both pellets and chips) /oil/gas } \\
\text { boilers }\end{array}$ \\
\hline & Micro-CHP technologies (fuel cells/CHP) \\
\hline & Thermal storage, Batteries and ice storage \\
\hline & Chillers (absorption and compression) \\
\hline \multirow{6}{*}{ 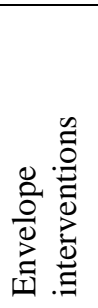 } & Roof insulation \\
\hline & Wall insulation \\
\hline & Replacement of windows \\
\hline & Floor insulation \\
\hline & Window replacement and wall insulation \\
\hline & Full retrofitting \\
\hline \multirow{3}{*}{ 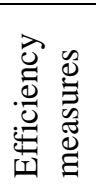 } & Ventilation strategies (heat recovery) \\
\hline & Lighting improvements \\
\hline & Electric device improvements $(\mathrm{A}++)$ \\
\hline
\end{tabular}

\section{Energy demand calculations}

Energy demand calculations for archetypical buildings are performed using the tool CESAR "Combined Energy Simulation and Retrofitting" (Wang et al., 2018). This tool utilizes the building simulation engine EnergyPlus (NREL, 2015) to calculate hourly electricity, heat and cooling demand profiles of buildings within a district over a period of one year. Geo-spatial information pertaining to building floorplans and their height (2.5D shape) is used to represent the geometry of buildings. Neighbouring buildings are considered as shading objects. Additional input information for the simulations pertains to: age, type, and the primarily used energy carriers for heating and domestic hot water. Information on building type and age is used to assign archetypical constructions to the different buildings. Thereby 9 different age classes are taken into account. For each age class typical constructions including their thermal properties are identified and randomly assigned to buildings within this building class (Wang et al. 2018). Energy carriers for heating and DHW are required for the conversion of energy demand into energy consumption. Furthermore, information on energy carriers used by individual buildings is used to determine its energy related emissions. An additional module of CESAR allows for evaluation of different envelope and other energy efficiency measures in addition to the current energy demand of the buildings.

The tool is applied on the selected building set. To account for climatic differences, Switzerland is clustered into different climatic zones. Fifty-two respective weather files are used for the corresponding region and allocated to the archetypes within these regions. Simulations are conducted for the current situation of buildings and additionally for the set of different retrofitting interventions (as per Table 2). Results are then further processed and given to the optimization framework as input information.

\section{Optimization framework}

In order to identify most promising retrofitting strategies (for both the building envelope and energy supply systems) an optimization tool based on the energy hub approach is utilized. The approach is based on a MILP optimization framework (Wu et al. 2017, Mavromatidis et al. 2014). To identify multi-objective (cost and $\mathrm{CO}_{2}$ ) optimum solutions the epsilon constraint method is deployed. Thereby the two objective functions for annualized costs and life cycle environmental impacts are considered. The generated energy demand profiles together with existing energy supply options (grid electricity, natural gas, oil or district heating), renewable energy potentials (such as solar, biomass or ground source heat) of individual buildings are taken as input to the model. The life-cycle emissions values for all energy carriers are found in Table 3. 
Table 3: Energy carrier prices and life-cycle emissions (including embodied emissions) per kWh (KBOB, 2016)

\begin{tabular}{|c|c|c|}
\hline Energy Carrier & $\begin{array}{c}\text { Price } \\
(\mathrm{CHF} / \mathrm{kWh})\end{array}$ & $\begin{array}{c}\text { Life-cycle } \\
\text { emissions }(\mathrm{kg} \\
\mathrm{CO} 2-\mathrm{eq} / \mathrm{kWh})\end{array}$ \\
\hline Grid electricity & 0.237 & 0.121 \\
\hline Heating oil & 0.101 & 0.301 \\
\hline $\begin{array}{c}\text { Wood pellets } \\
\text { (biomass) }\end{array}$ & 0.125 & 0.027 \\
\hline Natural gas & 0.120 & 0.228 \\
\hline District heating & 0.120 & 0.089 \\
\hline
\end{tabular}

Demand profiles are further processed to identify typical days, which are then used for the optimizations. Additionally, system options which are mentioned in table 2 are implemented into the optimization framework which pertain to: biomass boilers, micro combined heat and power plants (CHP), air source heat-pumps (ASHP), ground source heat-pumps (GSHP), photovoltaic panels (PV), solar thermal collectors (ST), oil and gas boilers, compression and absorption chillers as conversion technologies and hot water thermal storage tanks, ice storage and batteries as storage technologies. The building envelope retrofitting scenario and energy efficiency measures are implemented as additional decision variables within the optimization framework. The resulting energy hub configuration is depicted in the following figure.

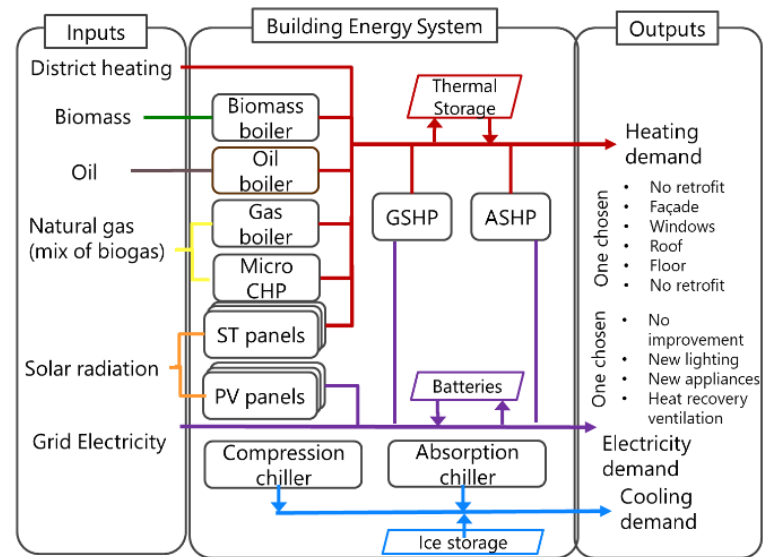

Figure 2: Energy hub layout with possible system and demand side measures

\section{Results and Discussion}

\section{Archetypical buildings}

The clustering of different building characteristics resulted in 500 archetypes for SFH and 500 archetypes for MFH. Relevant building features, which distinguish the different archetypes are municipality-code, floor area, building height, construction period, energy carrier for heating, energy carrier for DHW, number of residents, and number of dwellings. Figure 3 shows a map of
Switzerland along with the geographic location of the resulting archetypes. It can be seen that archetypes are distributed over the whole country and all climatic zones of Switzerland. Furthermore, it can be seen that most archetypes are located in the densely populated areas around bigger cities such as Zurich, Basel and Geneva.

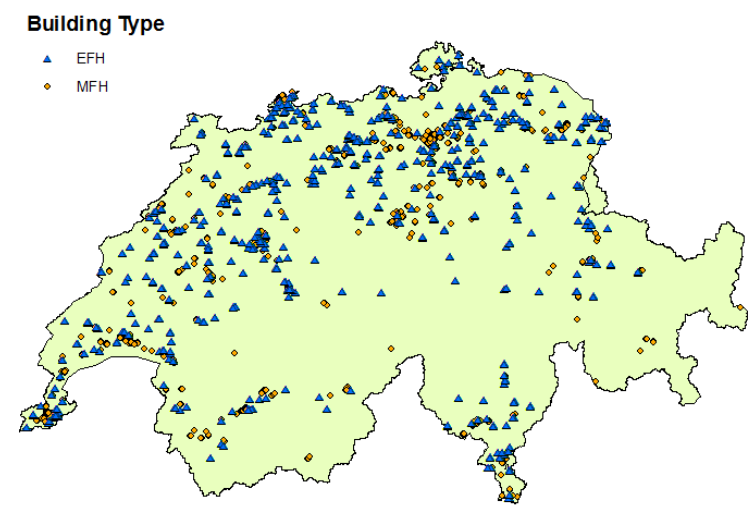

Figure 3: Identified Archetypes for single (SFH) and multifamily houses (MFH)

\section{Building envelope interventions}

For the 500 archetypes, the current energy demand for space heating, domestic hot water, cooling and electricity is calculated using the CESAR tool. Additionally different partial-retrofitting building envelope scenarios are examined which pertain to roof, ground or wall insulation or change in windows or combination of those measures. The distribution of resulting heating loads of the different age categories of buildings are shown in Figure 4. This figure shows that in the current state of the buildings, the distribution of energy demand is much more pronounced compared to buildings, which are already retrofitted. This effect is mainly seen for old buildings and less in newer buildings. The most effective individual envelope intervention is, in this case, the insulation of roofs or windows, which shows that energy demand can be reduced within a range of 20 to $30 \%$ by retrofitting this single measure. The resulting energy demand of building envelope retrofitting interventions can be examined in this way, however the optimal selection of each measure, considering the extra cost and embodied emissions included in the retrofit material and installation, to reach $\mathrm{CO}_{2}$ targets is difficult to extract. In a next step, the demand reduction, retrofit costs, and retrofit embodied emissions are used as input information in the optimization framework. 

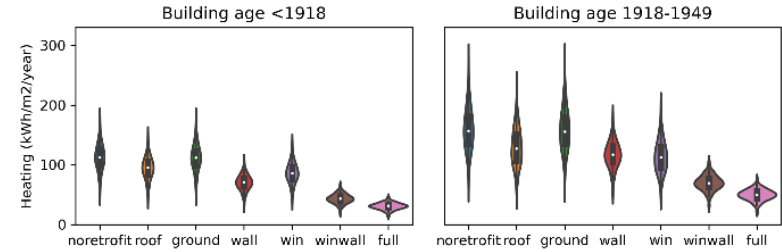

Building age 1950-1979

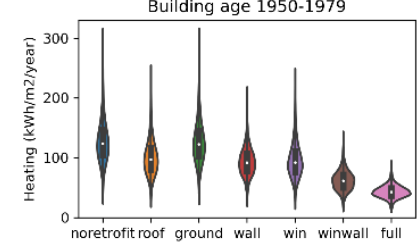

Building age 1980-1994

Building age 1995-2000
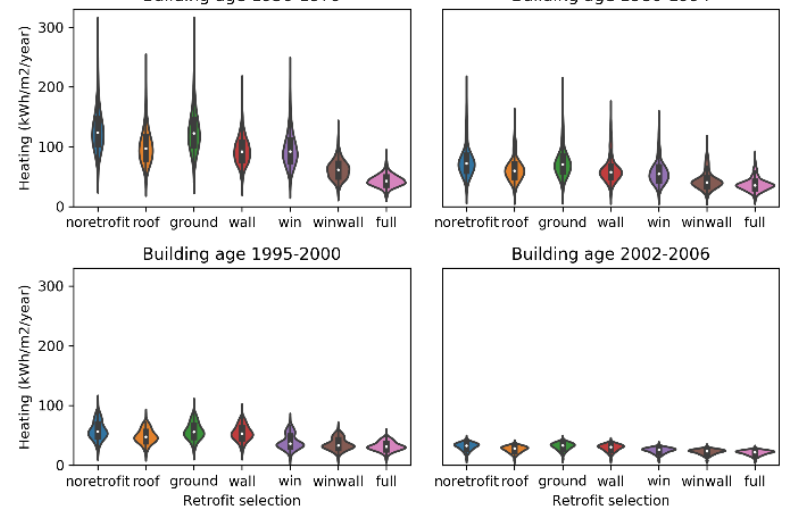

Building age 2002-2006

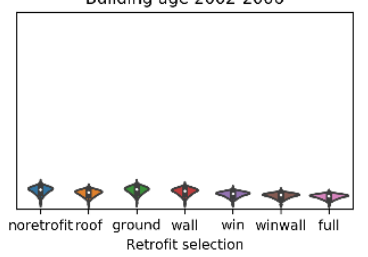

Figure 4: Violin plots of the distribution in energy consumption for different retrofitting scenarios per age class of SFH

\section{Optimal retrofitting measures}

For a subset of $50 \mathrm{SFH}$ and $50 \mathrm{MFH}$ archetypes, which represent $75 \%$ of all buildings in the residential building sector, the optimization framework for building envelope and system interventions is deployed. Thereby a multicriteria analysis of costs and $\mathrm{CO}_{2}$ emissions is conducted, which results in 10 Pareto optimal solutions which contain the fully cost optimal solution, the fully $\mathrm{CO}_{2}$ optimal solution, and 8 intermediate optimal solutions. Figure 5 shows the distribution of average heating system capacity per $\mathrm{m}^{2}$ for all archetypes for the 10 Pareto points, ranging from cost to $\mathrm{CO}_{2}$ optimum. Likewise, Figure 6 shows the distribution of the optimal building envelope interventions for the 10 Pareto optimal solutions. Results in terms of heating system show a shift from fossil fuel based heating systems (such as oil or gas boilers) to renewable based systems such as biomass boilers and photovoltaic panels, and highly efficient technologies like air-source heat pumps. It can be seen that in case of SFH the most prevailing heating system selection pertains to biomass boilers, whereas for MFH mainly ASHP are selected. This is due to a restriction of availability in the biomass potential for individual buildings. Switzerland would like to reduce its $\mathrm{CO}_{2}$ emissions until 2050 to one fourth compared to current emissions, which shall act as a basis to reach the goals of the 2000-Watt society in the building sector. In order to achieve this, overall $\mathrm{CO}_{2}$ emissions should be reduced to $10 \mathrm{~kg} \mathrm{CO}-\mathrm{eq} / \mathrm{m}^{2}$ for construction and operation of retrofitted buildings (SIA 2011). This goal would be achieved with all Pareto solutions ranging from 7-10 in Figures 5 and 6. Figure 7 shows additionally for all Pareto points and archetypes the system and envelope retrofitting selection and which $\mathrm{CO}_{2}$ emissions can be achieved. As can be seen from this Figure, system solutions that reach the target are mainly
ASHP and biomass boilers due to the very low $\mathrm{CO}_{2}$ impact of these systems. Only few buildings, which have an oil or gas boiler installed, are able to reach the $10 \mathrm{~kg}$ $\mathrm{CO}_{2}$-eq $/ \mathrm{m}^{2}$ threshold. However, in terms of envelope retrofitting optimal, the solutions differ quite significantly and range from no retrofitting to full retrofitting of the building envelope. These results show quite clearly that the optimal solution depend significantly on the initial state of the building and its boundary conditions. Figure 8 shows an average Pareto curve for SFH and MFH of all building archetypes. It is interesting to see that solutions for MFH are significantly cheaper in terms of costs and $\mathrm{CO}_{2}$ emissions.

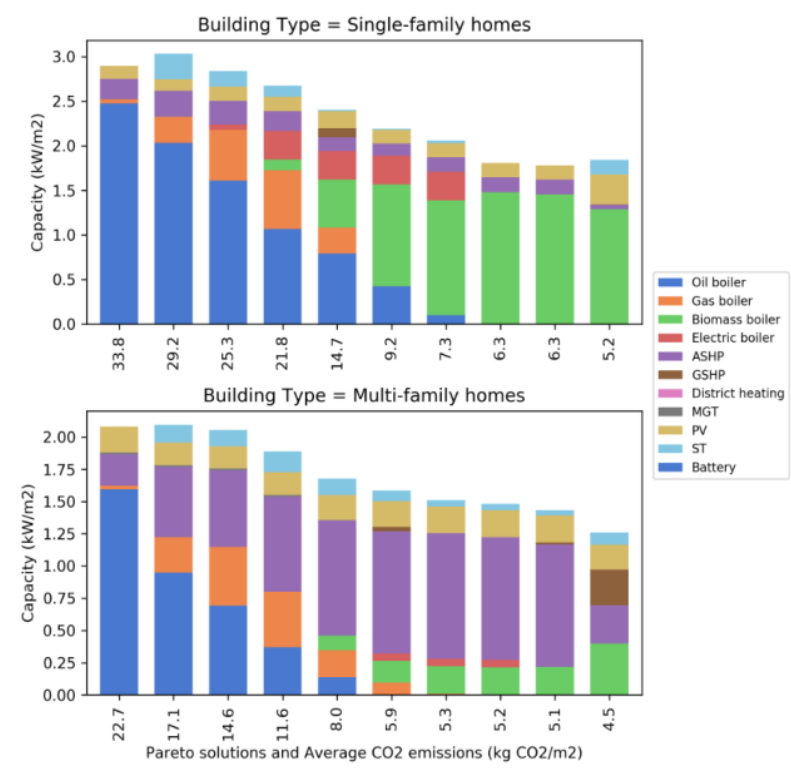

Figure 5: Distribution of average heating system capacity for the 10 Pareto optimal solutions for 50 archetypes, ranging from cost to $\mathrm{CO}_{2}$ optimum. 


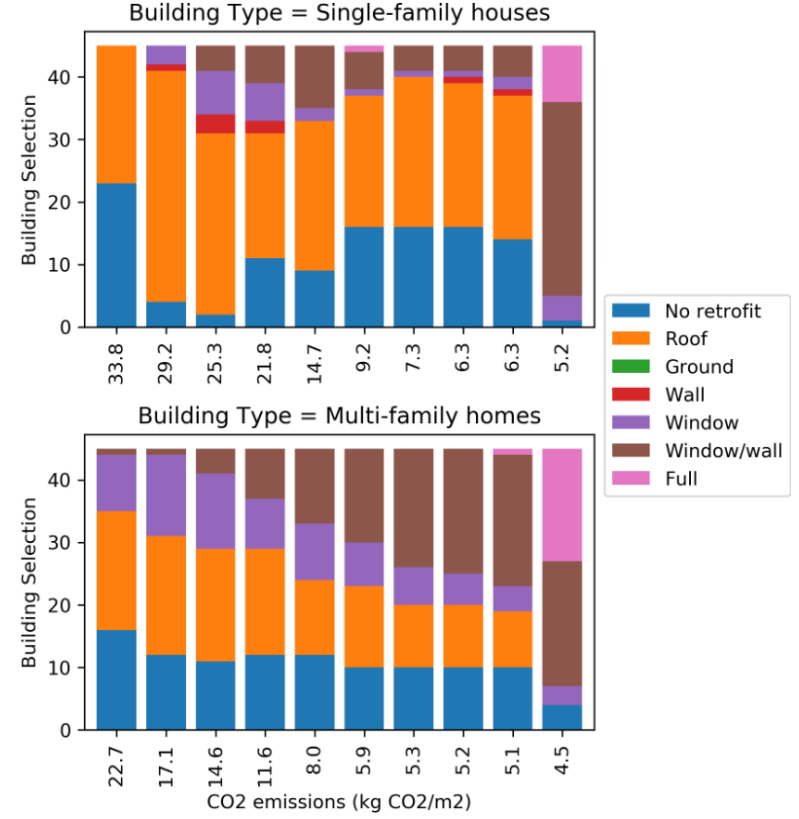

Figure 6: Distribution of optimum envelope retrofitting scenario for the 10 Pareto optimal solutions for 50 archetypes, ranging from cost to $\mathrm{CO}_{2}$ optimum.
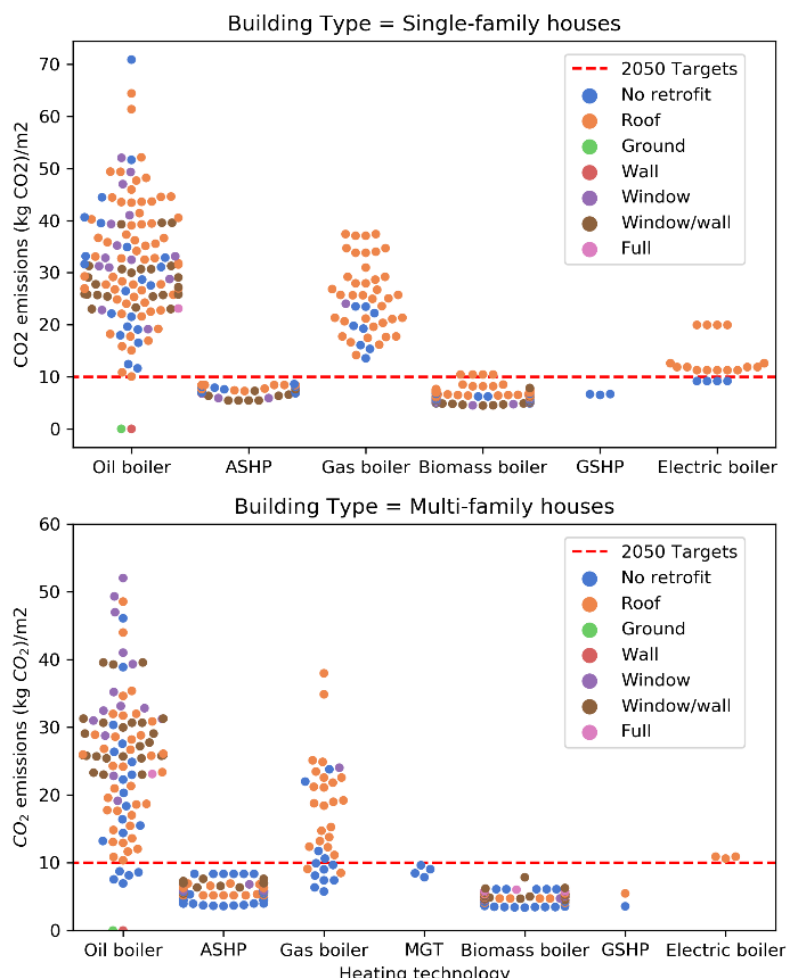

Figure 7: Distribution of Pareto optimal solutions for archetype buildings depending on their $\mathrm{CO}_{2}$ emissions.

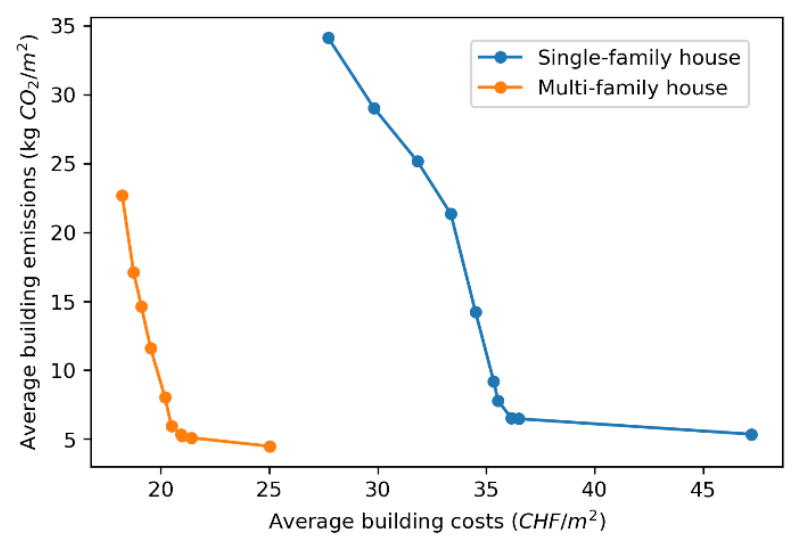

Figure 8: Average Pareto fronts for SFH and MFH of all archetypes.

From all solutions which reach the target of $10 \mathrm{~kg} \mathrm{CO}_{2}-$ $\mathrm{eq} / \mathrm{m}^{2}$, combination of measures are selected which occur the most frequently. These are shown in Table 4 for SFH and Table 5 for MFH. The set of 6 identified combinations represent $74 \%$ and $60 \%$ respectively, for $\mathrm{SFH}$ and $\mathrm{MFH}$ respectively, of all solutions that were able to meet the targets for all buildings. Identified measures pertain to roof retrofitting or window replacement and façade insulation together with PV installation. In terms of heating systems, biomass seems to be the most favourable option for SFH, while ASHPs can also be attractive, particularly for MFH.

Table 4: The identified most significant measures for SFH

\begin{tabular}{cccc}
\hline $\begin{array}{c}\text { Retrofit } \\
\text { selection }\end{array}$ & $\begin{array}{c}\text { Heating } \\
\text { system }\end{array}$ & Other & Frequency (\%) \\
\hline Roof & Biomass & - & 17 \\
Roof & Biomass & PV & 15 \\
No retrofit & Biomass & PV & 13 \\
No retrofit & Biomass & - & 12 \\
Window-wall & Biomass & PV+Battery & 11 \\
Window-wall & ASHP & PV & 6 \\
\hline & & & $74 \%$ \\
\hline
\end{tabular}

Table 5: The identified most significant measures for $\mathrm{MFH}$

\begin{tabular}{cccc}
\hline $\begin{array}{c}\text { Retrofit } \\
\text { selection }\end{array}$ & $\begin{array}{c}\text { Heating } \\
\text { system }\end{array}$ & Other & Frequency (\%) \\
\hline Window-wall & ASHP & PV & 23 \\
Window-wall & Biomass & PV & 14 \\
Window & ASHP & PV & 9 \\
Full retrofit & GSHP & & 9 \\
No retrofit & ASHP & PV+Battery & 5 \\
\hline
\end{tabular}




\section{Conclusions}

In this paper, a framework is presented which can be used to identify an optimal set of building measures for a large building data set. The approach is based on a simulation and optimization framework which uses a multi-criteria decision analysis based on costs and $\mathrm{CO}_{2}$ emissions to identify the optimal solutions. Furthermore, a clustering analysis is presented which allows for representation of the heteroginity of the building stock based on a set of building characteristics. The developed methodology can be used to assess the effectiveness of energy efficiency measures to reach emission reduction targets, but also allows to upscale solutions to the overall building stock of regions or countries to identify their potential impact.

The developed approach is applied to the overall residential building stock of Switzerland, which resulted in 500 archetypes for SFH and $\mathrm{MFH}$, for which the cost and $\mathrm{CO}_{2}$ optimum retrofitting solutions are identified. Results show that windows and roof retrofits are generally, the most cost-effective out of the investigated retrofit solutions. For older buildings, often a windowfaçade retrofit is required to lower the energy usage. The ideal energy system consists of an air source heat pump, a heat storage, and photovoltaic panels. The analysis also finds that a building's age is a major factor to decide whether or not these ideal solutions should be implemented. Results further suggest, that a change from a fossil fuel based heating system is required for almost all buildings in order to reach climate targets of Switzerland. A set of optimal solutions is identified, which are the most effecitive measures for the Swiss building stock. These solutions cover $74 \%$ of all SFH solutions and $60 \%$ of all MFH solution combinations that meet the targets of $10 \mathrm{~kg} \mathrm{CO} / \mathrm{m}^{2}$. Evaluated solutions usually consist of a change to biomass boilers or heat pumps (ASHP or GSHP), insulation of roof or replacement of windows combined with façade insultion (often require for older buildings) and additionally the installation of photovoltaic panels. It is predicted that battery technology is not yet cost effective enough and the embodied emissions are currently too high for indstallation in individual homes.

If all buildings that require an update were retrofitted and/or had their energy system modernised to fit the ideal solution, emissions could potentially be reduced by as much as $78 \%$ and $80 \%$ respectively. These results show that the Swiss residential building sector has enormous potential for improvement in terms of sustainability.

\section{Acknowledgements}

This research has been financially supported by Innosuisse within the Swiss Competence Center of Energy Research - Future Energy Efficient Buildings and Districts SCCER FEEB\&D (CTI.1155000149) and by SNF and EnDK within the NFP 70 program "Energiewende" project EnTer (407040_153890). Authors would also like to acknowledge all project partners of the EnTeR project.

\section{References}

BFS (2013). Gebäude und Wohnungsstatistik (GWS), Bundesamt für Statistik.

Koordinationskonferenz der Bau- und Liegenschaftsorgane der öffentlichen Bauherren. (2016). Ökobilanzdaten Im Baubereich.

Mavromatidis, G., Evins, R., Orehounig, K., Dorer, V., Carmeliet, J. (2014). Multi-objective optimization to simultaneously address energy hub sizing, layout and scheduling using a linear formulation. 4th international conference on engineering optimization, September 8th-11th 2014, Lisbon, Portugal.

NREL (2015). EnergyPlus. https://energyplus.net/

Pedregosa, F., G. Varoquaux, A. Gramfort, and V. Michel. (2011). "Scikit-Learn: Machine Learing in Python." Journal of Machine Learning Research 12:2825-30.

Prognos (2012). Die Energieperspektiven für die Schweiz bis 2050, Bundesamt für Energie. https://www.prognos.com/publikationen/allepublikationen/292/show/7f9a4382d75cc4003214730 6d423aaca/

Schneider, S. (2018). SCCER Swiss Competence Center for Energy Research. Geodependent energy supply/demand web service. http://wisesccer1.unige.ch/.

SIA (2011). SIA 2040-Effizienzpfad Energie, Swiss Society of Engineers and Architects.

Swisstopo, (2016). https://www.swisstopo.admin.ch/ .

Wang, D., Landolt, J., Mavromatidis, G., Orehounig, K., Carmeliet, J. (2018). CESAR: A bottom-up housing stock model for Switzerland to address sustainable energy transformation strategies. Energy and Buildings Vol 169, 9-26.

Wu, R., Mavromatidis, G., Orehounig, K., Carmeliet, J. (2017). Multi-objective optimisation of energy systems and building envelope retrofit in a residential community. Applied Energy 190, 634-649. 